\title{
Teste Nacional de Desempenho do Estudante do Brasil (Enade), 2014 e 2017: Uma análise de questões relacionadas à probabilidade
}

\author{
Brazil's National Student Performance Test (Enade), 2014 and 2017: An analysis of \\ probability-related questions
}

\author{
Auriluci de Carvalho Figueiredo*ab; Cileda de Queiroz e Silva Coutinho ${ }^{\mathrm{a}}$ \\ aPontifícia Universidade Católica de São Paulo. SP, Brasil. \\ ${ }^{b}$ Universidade Metropolitana de Santos. SP, Brasil. \\ *E-mail: aurilucy@uol.com.br
}

\begin{abstract}
Resumo
Neste artigo discutimos o Exame Nacional de Desempenho de Estudantes (Enade) frente a conteúdos probabilísticos que foram avaliados nas versões aplicadas a cursos de licenciatura em matemática em 2014 e 2017 . O Enade avalia o desempenho de estudantes de graduação em conteúdos programáticos previstos nas diretrizes curriculares nacionais do respectivo curso. A pesquisa qualitativa documental analisou documentos oficiais que regem a educação básica, para identificar quais conhecimentos probabilísticos são requeridos nessa fase do ensino, bem como documentos que regem a licenciatura em matemática e as duas provas citadas, com destaque para as questões que envolvem conhecimentos de probabilidade, de modo a identificar quais elementos do letramento probabilístico, segundo o modelo proposto por Gal, estão nelas presentes. As análises foram feitas à luz da teoria antropológica do didático, de Chevallard, com o olhar da organização praxiológica, no intuito de verificar em que condições didáticas tais praxiologias avaliam os elementos do letramento probabilístico do futuro professor de matemática. Nas questões analisadas, constataram-se itens para cuja resolução o conhecimento de probabilidade voltado somente à educação básica não bastaria. A presença do letramento probabilístico analisado pelo modelo de Gal, considerando as praxiologias identificadas, aponta um aumento nos elementos cognitivos, sem que isso, porém, represente presença de elementos disposicionais.
\end{abstract}

Palavras-chave: Probabilidade. Praxiologias. Letramento Probabilístico

\begin{abstract}
In this article we discuss the National Student Performance Exam (Enade) in terms of the probabilistic contents found in the 2014 and 2017 versions applied to Brazilian teaching-degree programs in mathematics. The exam evaluates the performance of undergraduate students on curriculum contents defined in the national curricular guidelines for the program attended. This qualitative desk research analyzed official guidelines for basic education (ages 6-17) to identify which probabilistic knowledge items are required in this phase of education, as well as official guidelines for teaching-degree programs in mathematics. Analysis of the 2014 and 2017 exams concentrated on questions involving probability-related knowledge, to identify which elements of probabilistic literacy, as per the model proposed by Gal, were present. The analyses were performed observing Chevallard's anthropological theory of the didactic, from the perspective of praxeological organization, to observe the didactic conditions under which these praxeologies can depict elements of probabilistic literacy among future mathematics teachers. The questions analyzed contained items whose resolution required a wider knowledge of probability than that circumscribed to basic education grades. Considering the praxeologies in operation, the probabilistic literacy elements identified in the analysis revealed an increased presence of cognitive elements, while failing to indicate the presence of dispositional elements, as per Gal's framework.
\end{abstract}

Keywords: Probability. Praxeologies. Probabilistic Literacy.

\section{Introdução}

Apresentaremos os resultados de uma pesquisa qualitativa documental sobre formação probabilística do futuro professor de matemática.

Santos (2015) já apontara serem poucos os estudos sobre esse tema, situação que Rodrigues (2018) subsequentemente confirmou. Constatamos que alguns dos estudos publicados versam sobre livros didáticos da escola básica, os quais são materiais didáticos que fazem parte da prática docente de futuros professores e dos já egressos de licenciaturas. As pesquisas de Goulart (2007) e Coutinho (2013, 2019) sobre esse teor adotam o mesmo quadro teórico - a teoria antropológica do didático (TAD) - e apontam ser baixa a diversidade dos tipos de atividade oferecidos ao professor em livros didáticos.
No Brasil, conhecimentos sobre probabilidade vêm sendo cobrados em provas oficiais da educação básica, como o Exame Nacional do Ensino Médio (ENEM), o Sistema de Avaliação da Educação Básica (SAEB), a Prova Brasil e o Sistema de Avaliação de Rendimento Escolar do Estado de São Paulo (Saresp). Tanto os Parâmetros Curriculares Nacionais (PCN) (Brasil, 1998, 2002b) quanto a Base Nacional Comum Curricular (BNCC) (Brasil, 2018a), que regem a educação básica no país, explicitam que, ao estudar probabilidade, o aluno deve perceber que em seu cotidiano há muitos eventos de natureza aleatória. Deve conseguir identificar possíveis resultados destes.

A cada três anos os alunos de todas as licenciaturas prestam o Exame Nacional de Desempenho de Estudantes (Enade), que avalia os conhecimentos construídos ao longo da formação 
universitária desses estudantes. A formação dos professores da educação básica é regida por documentos oficiais, como as Diretrizes Curriculares das Licenciaturas (Brasil, 2002a, 2019) e as Diretrizes da Licenciatura em Matemática (Brasil, 2001), e neles buscamos identificar conhecimentos relativos à probabilidade, quer sejam voltados à educação superior ou à básica.

Analisaremos questões do Enade de 2014 e de 2017 que envolveram conhecimentos de probabilidade, de modo a identificarmos a presença de elementos de letramento probabilístico (Gal, 2005). A análise se guiará pela TAD, particularmente sob o olhar da organização praxiológica, visando verificar sob quais condições didáticas tais praxiologias avaliam os elementos do letramento probabilístico do futuro professor de matemática. Discutiremos essas praxiologias mais adiante no texto.

\section{A Probabilidade em Documentos Oficiais}

O ensino de probabilidade recebe destaque na BNCC (Brasil, 2018a), em que faz parte, junto com a estatística, de uma das cinco unidades temáticas focalizadas. No eixo 'Probabilidade e estatística', o documento sugere que esses objetos de conhecimento sejam trabalhados desde os anos iniciais do ensino fundamental, visando capacitar os alunos a construir espaços amostrais de eventos equiprováveis utilizando árvores de possibilidades, princípio multiplicativo ou simulações. Os PCN (Brasil, 1997) propõem que os alunos tenham contato com as ideias de aleatoriedade e de chance desde os anos iniciais, sempre em espaços equiprováveis e sem quantificação, mas apenas como ideias intuitivas.

O Quadro 1 sumariza os objetos de conhecimento apontados pela BNCC para os anos finais do ensino fundamental, com as respectivamente habilidades a serem desenvolvidas.

Quadro 1 - Objetos de conhecimento e habilidades propostos na Base Nacional Comum Curricular

\begin{tabular}{|c|c|}
\hline Objeto & Habilidade \\
\hline $\begin{array}{l}\text { Cálculo de probabilidade } \\
\text { como razão entre número de } \\
\text { resultados favoráveis e total } \\
\text { de resultados possíveis em } \\
\text { espaço amostral equiprovável. } \\
\text { Cálculo de probabilidade por } \\
\text { meio de muitas repetições de } \\
\text { um experimento (frequências } \\
\text { de ocorrência e probabilidade } \\
\text { frequentista). }\end{array}$ & $\begin{array}{l}\text { (EF06MA30) Calcular a } \\
\text { probabilidade de um evento } \\
\text { aleatório, expressando-a } \\
\text { por número racional (forma } \\
\text { fracionária, decimal e } \\
\text { percentual), e comparar esse } \\
\text { número com a probabilidade } \\
\text { obtida por meio de } \\
\text { experimentos sucessivos. }\end{array}$ \\
\hline $\begin{array}{l}\text { Experimentos aleatórios: } \\
\text { espaço amostral e estimativa } \\
\text { de probabilidade por meio de } \\
\text { frequências de ocorrência. }\end{array}$ & $\begin{array}{l}\text { (EF07MA34) Planejar } \\
\text { e realizar experimentos } \\
\text { aleatórios ou simulações } \\
\text { que envolvem cálculo de } \\
\text { probabilidades ou estimativas } \\
\text { por meio de frequências de } \\
\text { ocorrência. }\end{array}$ \\
\hline
\end{tabular}

\begin{tabular}{|c|c|}
\hline $\begin{array}{l}\text { Princípio multiplicativo } \\
\text { da contagem. Soma das } \\
\text { probabilidades de todos os } \\
\text { elementos de um espaço } \\
\text { amostral. }\end{array}$ & $\begin{array}{l}\text { (EF08MA22) Calcular a } \\
\text { probabilidade de eventos } \\
\text { com base na construção de } \\
\text { espaço amostral e utilizando } \\
\text { o princípio multiplicativo. } \\
\text { Reconhecer que a soma das } \\
\text { probabilidades de todos os } \\
\text { elementos do espaço amostral } \\
\text { é igual a 1. }\end{array}$ \\
\hline $\begin{array}{l}\text { Análise de probabilidade de } \\
\text { eventos aleatórios: eventos } \\
\text { dependentes e independentes. }\end{array}$ & $\begin{array}{l}\text { (EF09MA20) Reconhecer, } \\
\text { em experimentos aleatórios, } \\
\text { eventos independentes e } \\
\text { dependentes e calcular } \\
\text { a probabilidade de sua } \\
\text { ocorrência nos dois casos. }\end{array}$ \\
\hline
\end{tabular}

Fonte: Brasil (2018).

Até 2018, ano em que a BNCC trouxe orientações para abordar a matemática no ensino fundamental, contavase apenas com os $\mathrm{PCN}$, nos quais a probabilidade é tópico também presente. Entre os exemplos disso, figuram a construção de espaço amostral e indicação da possibilidade de sucesso de um evento pelo uso de uma razão; a construção de espaço amostral utilizando o princípio multiplicativo e indicação da probabilidade de um evento por meio de uma razão; e a elaboração de experimentos e simulações para estimar probabilidades e verificar probabilidades previstas (Brasil, 1998).

Uma das diferenças entre os conteúdos desses documentos é que a BNCC inclui frequências de ocorrência e probabilidade frequentista, bem como análise de probabilidade de eventos aleatórios (eventos dependentes e independentes).

Entre os conteúdos probabilísticos, os PCN do ensino médio incluem "Probabilidade: possibilidades; cálculo de probabilidades" (Brasil, 2002b, p. 127), e os alunos devem desenvolver estratégias em atividades que envolvam:

- Reconhecer o caráter aleatório de fenômenos e eventos naturais, científico-tecnológicos ou sociais, compreendendo o significado e a importância da probabilidade como meio de prever resultados.

- Quantificar e fazer previsões em situações aplicadas a diferentes áreas do conhecimento e da vida cotidiana que envolvam o pensamento probabilístico.

- Identificar em diferentes áreas científicas e outras atividades práticas modelos e problemas que fazem uso de estatísticas e probabilidades. (Brasil, 2002b, p. 127-128).

Para o ensino médio, a BNCC redivide as unidades de matemática com base nas do ensino fundamental e propõe aproximações entre estes para a prática de elaboração curricular dessa área:

Essas unidades podem ser, entre outras, Números e Álgebra, Geometria e Medidas, e Probabilidade e Estatística. Utilizar estratégias, conceitos e procedimentos matemáticos para interpretar situações em diversos contextos, sejam atividades cotidianas, sejam fatos das Ciências da Natureza e Humanas, das questões socioeconômicas ou tecnológicas, divulgados por diferentes meios, de modo a contribuir para uma formação geral. (Brasil, 2018a, p. 542) 
O documento define como habilidades a desenvolver:

(EM13MAT311) Identificar e descrever o espaço amostral de eventos aleatórios, realizando contagem das possibilidades, para resolver e elaborar problemas que envolvem o cálculo da probabilidade.

(EM13MAT312) Resolver e elaborar problemas que envolvem o cálculo de probabilidade de eventos em experimentos aleatórios sucessivos.

(EM13MAT511) Reconhecer a existência de diferentes tipos de espaços amostrais, discretos ou não, e de eventos, equiprováveis ou não, e investigar implicações no cálculo de probabilidades. (Brasil, 2018a, p 537)

Embora tais habilidades estejam listadas na área 'Matemática e suas tecnologias' (como mostra a sigla 'MAT' em seus códigos), a probabilidade não se restringe à matemática nesse documento, constando também em 'Ciências da natureza e suas tecnologias' (CNT):

(EM13CNT205) Interpretar resultados e realizar previsões sobre atividades experimentais, fenômenos naturais e processos tecnológicos, com base nas noções de probabilidade e incerteza, reconhecendo os limites explicativos das ciências. (Brasil, 2018a, p. 557).

Tal habilidade tem relação com a competência de "Analisar e utilizar interpretações sobre a dinâmica da Vida, da Terra e do Cosmos para elaborar argumentos, realizar previsões sobre o funcionamento e a evolução dos seres vivos e do Universo, e fundamentar e defender decisões éticas e responsáveis" (Brasil, 2018a, p. 553).

Acreditamos que tais habilidades e competências permitem lidar de modo mais desenvolto com situações da vida cotidiana.

A licenciatura em matemática é regida por documentos oficiais, entre os quais figuram as Diretrizes Curriculares Nacionais (DCN) para a Matemática (Brasil, 2001); as DCN para a Formação de Professores da Educação Básica, em Nível Superior, Curso de Licenciatura, de Graduação Plena (Brasil, 2002a); e, previstas para 2022, as DCN para a Formação Inicial de Professores para a Educação Básica e Base Nacional Comum para a Formação Inicial de Professores da Educação Básica (BNC-Formação) (Brasil, 2019).

Nas DCN específicas da licenciatura em matemática (Brasil, 2001), probabilidade e estatística não constam entre os conteúdos específicos obrigatórios para a formação docente, os quais abrangem cálculo diferencial e integral, álgebra linear, fundamentos de álgebra, fundamentos de geometria e geometria analítica (Brasil, 2001). O documento menciona como obrigatórios os "Conteúdos matemáticos presentes na educação básica nas áreas de Álgebra, Geometria e Análise" (Brasil, 2001, p. 5). Assim, ao não explicitar conteúdos obrigatórios referentes à probabilidade, as DCN não trazem elementos para o desenvolvimento do letramento probabilístico desses licenciandos.

As DCN para a Formação de Professores da Educação Básica (Brasil, 2002a), por sua vez, apontam que se deve construir uma relação entre a formação docente e as normas instituídas para a educação básica, seguindo-se para tanto recomendações "constantes dos Parâmetros e Referenciais Curriculares para a educação básica elaborados pelo Ministério da Educação" (Brasil, 2002a, p. 4).

Acreditamos que construir tal relação requer obrigatoriedade de conteúdos de probabilidade na licenciatura em matemática, visando o letramento probabilístico, uma vez que tais conteúdos são recomendados nos PCN (Brasil, 1998) e na BNCC (Brasil, 2018a), que sugerem elementos para esse desenvolvimento.

Quanto às licenciaturas, uma das indicações das BNCFormação (Brasil, 2019) é que os currículos dos cursos destinados à formação inicial de professores estabeleçam relações com as aprendizagens prescritas na BNCC da educação básica. Para os currículos das licenciaturas em matemática, as BNC-Formação prescrevem "Grupo II: 1.600 [...] horas, para a aprendizagem dos conteúdos específicos das áreas, componentes, unidades temáticas e objetos de conhecimento da BNCC, e para o domínio pedagógico desses conteúdos" (Brasil, 2019 p. 7). Fica claro nesse documento que tanto as unidades temáticas definidas na BNCC (2018) para matemática na educação básica quanto os objetos do conhecimento (conteúdos) devem constar na formação dos professores. Assim, destacamos a probabilidade como nosso foco de estudo, devendo ser abordada ao longo da formação inicial do professor de matemática, em orientação documental explícita, diferentemente do que se percebe nas DCN (2002a). Nesta mesma linha de argumentação, defendemos também novas diretrizes curriculares específicas para a licenciatura em matemática que orientem a construção de projetos pedagógicos de curso (PPC) e, consequentemente, suas matrizes curriculares.

Embora nem a probabilidade nem a estatística constem nas DCN (2001) como obrigatórias na licenciatura em matemática, Viali (2008) analisou uma amostra de 125 currículos dessas licenciaturas e observou que, dentre as disciplinas ministradas, a que focaliza probabilidade e estatística tem tipicamente carga de $60 \mathrm{~h}$ e apresenta a estatística como uma disciplina da matemática. Rodrigues e Silva (2019), ao analisarem os PPC de 190 licenciaturas, encontraram 125 que contemplam estatística e probabilidade e um com a disciplina 'Aprendizagem de estatística no ensino fundamental e médio'.

Embora as DCN de licenciatura em matemática não obriguem ao ensino de probabilidade, o fato de que o futuro professor necessita de tais conteúdos para suas práticas docentes na escola básica (além da exigência desse conteúdo no Enade) torna necessária sua abordagem nesses cursos.

\section{A Probabilidade em Documentos Relativos ao Enade e ENEM}

Analisando questões do Enade de 2005, 2008 e 2011 sobre o ensino de estatística e probabilidade, Goulart (2015, p. 95) aponta que:

Todas as questões do Enade que abordam Probabilidade e 
Estatística não apresentam grau de dificuldade maior que as questões apresentadas no ENEM. Trata-se portanto de questões que poderiam ter sido propostas pelo ENEM, já que no referencial de conteúdos curriculares para a elaboração do componente específico da área de Matemática os conteúdos de Probabilidade e Estatística aparecem somente como conteúdos matemáticos da Educação Básica para a realização desse exame, isto é, a organização matemática identificada no Enade é a mesma identificada no ENEM.

Goulart (2015) associa tal diferença ao fato de não constarem tais conteúdos nas DCN de licenciatura em matemática, embora figurem nas provas do Enade de 2014 e 2017, já que são mencionados no artigo 7. ${ }^{\circ}$ do edital desse exame (Brasil, 2014), na parte relativa ao componente específico da área de matemática.

O ENEM foi instituído em 1998 como procedimento de avaliação do desempenho do aluno, visando "conferir ao cidadão parâmetro para autoavaliação, com vistas à continuidade de sua formação e à sua inserção no mercado de trabalho", "criar referência nacional para os egressos de qualquer das modalidades do ensino médio", "fornecer subsídios às diferentes modalidades de acesso à educação superior" e "constituir-se em modalidade de acesso a cursos profissionalizantes pós-médio" (Brasil, 1998, p. 1).

Nessa avaliação é possível observar aspectos do letramento probabilístico que são cobrados de estudantes que estão terminando o ensino médio. Com a implantação do Sistema de Seleção Unificada (Sisu) em 2009, o ENEM tornou-se a principal via de ingresso às universidades federais, o que nos leva a refletir sobre a presença de conteúdos probabilísticos nesse exame. No Enade, por sua vez, a pontuação não é atribuída ao estudante, mas tem efeito avaliativo sobre seu curso específico e para a instituição que o ministra, seja ela pública ou privada.

A matriz de referência do ENEM lista como competências requeridas no campo da probabilidade:

Competências da Área 7: Compreender o caráter aleatório e não determinístico dos fenômenos naturais e sociais e utilizar instrumentos adequados para medidas, determinação de amostras e cálculos de probabilidade para interpretar informações de variáveis apresentadas em uma distribuição estatística. (Brasil, 2009, p. 6-7).

As habilidades correspondentes às competências da Área 7 são as de calcular medidas de tendência central ou de dispersão de um conjunto de dados expressos em uma tabela de frequências de dados agrupados (não em classes) ou em gráficos (Habilidade 27), resolver situação-problema que envolva conhecimentos de estatística e probabilidade (Habilidade 28), utilizar conhecimentos de estatística e probabilidade como recurso para a construção de argumentação (Habilidade 29) e avaliar propostas de intervenção na realidade utilizando conhecimentos de estatística e probabilidade (Habilidade 30) (Brasil, 2009).

De 2009 a 2019, as questões sobre probabilidade no ENEM variaram de uma a quatro (Quadro 2).
Quadro 2 - Questões sobre probabilidade no ENEM

\begin{tabular}{|c|l|}
\hline Quantidade & \multicolumn{1}{|c|}{ Anos } \\
\hline 1 & 2016 \\
\hline 2 & $2012,2014,2019$ \\
\hline 3 & $2009,2011,2015,2017$ \\
\hline 4 & $2010,2013,2018$ \\
\hline
\end{tabular}

Fonte: Dados da pesquisa.

Analisando 70 questões do ENEM de 2009 a 2016, Pereira e Sousa (2016) constataram naquelas que envolviam probabilidade e estatística apenas algumas das habilidades citadas da matriz de referência. Em seu estudo, destacam como habilidades que favorecem o desenvolvimento do letramento probabilístico as acima referidas como Habilidades 29 e 30 . Ambas têm relação direta com probabilidade.

\section{Referencial Teórico e Caminhos Metodológicos}

A pesquisa aqui relatada é de cunho qualitativo, de tipo estudo documental, nos termos de Fiorentini e Lorenzato (2009). Os dados coletados visam atingir o objetivo da pesquisa, de identificar as praxiologias presentes nas questões relativas à probabilidade formuladas nas provas do Enade de 2014 e 2017, analisando a presença de elementos do letramento probabilístico nos termos de Gal (2005).

Dessa forma, analisamos documentos oficiais para mapear os conhecimentos probabilísticos que se espera que o professor ensine em sua prática profissional na escola básica. Além desses documentos, analisamos também provas do Enade quanto às questões que abordaram probabilidade. Buscamos identificar os objetivos de tais questões, o problema a ser resolvido e formas de resolvê-lo, com suas respectivas justificativas (organização matemática).

Quanto ao letramento probabilístico, tomamos como referencial o modelo proposto por Gal (2005), que é constituído de componentes de dois tipos: cognitivos e disposicionais. Os cognitivos abrangem: grandes tópicos (abordagem com tópicos fundamentais: variação, aleatoriedade, independência, previsibilidade e incerteza), cálculos probabilísticos (maneiras de encontrar ou estimar a probabilidade de eventos), linguagem (termos e métodos usados para comunicar sobre probabilidade), contexto (compreender o papel e as implicações das questões probabilísticas nas mensagens em vários contextos, incluindo os cotidianos) e questões críticas (questões para refletir quando se lida com probabilidade). Os elementos disposicionais envolvem postura crítica; crenças e atitudes; e sentimentos pessoais sobre incerteza e riscos. Gal (2005) aponta que os dois tipos de elementos estão interligados, interagindo de forma complexa durante a aprendizagem. Adverte que focar o ensino de probabilidade apenas em parte desses elementos não bastará para desenvolver o letramento probabilístico dos estudantes, e ressalta: "exige-se atenção para a questão da transferência de competências na sala de 
aula para aprender as situações fora da sala de aula" (p. 58).

Para analisar as questões do Enade, tomamos também como referencial teórico a TAD (Chevallard, 1996, 1999), que "situa a atividade matemática e, em consequência, a atividade do estudo de Matemática, dentro do conjunto das atividades humanas e das instituições sociais" (Chevallard, 1999, p. 221).

Almouloud (2007, p. 111) ressalta a importância dessa teoria para a didática da matemática, por ser "uma evolução do conceito de transposição didática, inserindo a didática no campo da antropologia, focaliza os estudos das organizações praxiológicas didáticas pensadas para o ensino e a aprendizagem de organizações matemáticas".

A premissa básica da TAD (Chevallard, 1999) é que toda atividade humana realizada regularmente pode ser descrita por um mesmo modelo, que o autor resume na palavra 'praxiologia'.

No âmbito da TAD, Gascón (2003) elucida que uma organização matemática surge sempre como resposta a uma questão ou a um conjunto delas, e tal organização tem quatro componentes principais: tipos de problema, técnicas, teorias e tecnologias. Expõe que se contemplarmos as:

relações dinâmicas que são estabelecidas entre esses componentes, a fim de realizar a atividade matemática necessária para responder as questões matemáticas iniciais, (...) aparecem duas faces inseparáveis: a prática matemática o "práxis", $\{\mathrm{T} / \tau\}$, formada pelas tarefas, $\mathrm{T}$, e as técnicas matemáticas, $\tau$; e o "logos", $\{\theta, \Theta\}$, constituído pelo discurso matemático que justifica e interpreta esta prática e que estruturamos em dois níveis: a tecnologia, $\theta$, que faz referência direta com a prática, e a teoria, $\Theta$, que consiste em um segundo e último nível de justificação da prática (ou tecnologia da tecnologia). Ao unir as duas faces da atividade da matemática, práxis e logos, se obtém a noção de praxiologia matemática. (Gascón, 2003, p. 16).

Analisamos questões do Enade para identificar qual organização matemática estaria presente no estudo do objeto matemático 'probabilidade', traçando um esboço praxiológico das atividades matemáticas ao descrevê-las por meio dos quatro componentes citados.

Em síntese, podemos dizer que em torno de um conjunto de tarefas $\mathrm{T}$ encontra-se um trio formado por uma técnica capaz de executar esse conjunto de tarefas, uma tecnologia relativa a essa técnica e uma teoria relativa a esta tecnologia. O conjunto (sistema) assim formado é denominado praxiologia ou organização praxiológica relativa ao conjunto de tarefas $\mathrm{T}$.

Goulart (2015), mapeando as características das organizações praxiológicas presentes em livros didáticos do ensino médio relativas à estatística e à probabilidade, fornece um exemplo para ilustrar a relação entre esses quatro componentes (Quadro 3).
Quadro 3 - Análise de uma questão de livro didático do ensino médio à luz da teoria antropológica do didático

Questão 1: Jogam-se dois dados. Qual é a probabilidade de se obter 4 no primeiro dado se a soma dos resultados é 9?

Tarefa $\left(\mathbf{T}_{1}\right)$ : Calcular a probabilidade de um evento condicionado.

Técnica $\left(\mathbf{t}_{1}\right)$ : 1. Identificar o experimento aleatório e o espaço amostral.

2. Identificar o evento A: Obter 4 no primeiro dado.

3. Identificar o evento B: Obter soma 9 no lançamento de dois dados.

3. Calcular a probabilidade do evento A.

5. Calcular a probabilidade do evento B.

6. Calcular a probabilidade da intersecção do evento A com o evento B.

7. Calcular a probabilidade do evento $\mathrm{A}$, dado que o evento $\mathrm{B}$ ocorreu, utilizando.

Discurso teórico-tecnológico $[\boldsymbol{\theta}, \boldsymbol{\Theta}]$ : $\mathrm{O}$ conhecimento matemático envolvido neste bloco é o conceito de probabilidade condicional. Sejam A e B dois eventos de um espaço amostral e supondo que $\mathrm{P}(\mathrm{A})>0$, a probabilidade condicional de $\mathrm{B}$, dado $\mathrm{A}$, é definida por

Fonte: Adaptado de Goulart (2015).

Em termos de componentes cognitivos do letramento probabilístico (Gal, 2005), a questão requer cálculos probabilísticos, o contexto envolvido é o de jogos e a maneira de calcular cada uma das probabilidades envolve determinada linguagem, mas o enunciado da questão não favorece atitude crítica diante desse contexto - ou seja, o tipo de tarefa não permite o desenvolvimento de uma técnica na qual se observe a presença de todos os elementos do modelo de letramento probabilístico de Gal (2005). Podemos inferir que o exercício proposto avalia procedimentos de resolução, mas não o letramento do candidato.

\section{Análise das Questões do Enade}

De 2005 a 2017, foram poucas as questões do Enade envolvendo probabilidade: nenhuma em 2005, uma em 2011 e 2014 e duas em 2008 e 2017.

Adotando a TAD como referência, Goulart (2015) analisou as questões de probabilidade de 2008 e 2011, constatando que os conhecimentos de probabilidade necessários para resolvêlas eram os mesmo que no ENEM. Nelas identificou as tarefas de calcular a probabilidade e de calcular a probabilidade de um evento complementar. As técnicas identificadas foram as de identificar o experimento aleatório; descrever o espaço amostral do experimento aleatório; dentro do espaço amostral, identificar os resultados favoráveis ao evento que se quer estudar; calcular o número de casos favoráveis; identificar que o evento que se deseja estudar é o complementar ao item $a$; calcular a probabilidade do evento complementar; calcular o número de casos possíveis; e determinar a razão entre o número de casos favoráveis e o número de casos possíveis (definição clássica de probabilidade).

Diferentemente do que constatou Goulart (2015), identificamos no Enade de 2014 e 2017 uma questão envolvendo cálculo de probabilidade, cuja resolução requer 
conhecimentos da distribuição normal de probabilidade, conteúdo este não previsto nos documentos oficiais que regem a educação básica. No entanto, tal conteúdo é usualmente abordado na licenciatura em matemática.

Para melhor compreensão das possíveis diferenças nessas avaliações e para identificar quais conteúdos de probabilidade tal prova exige do futuro professor da educação básica, analisaremos questões do Enade de 2014 e 2017 (Quadros 4 a 6), comparando os achados com os de Goulart (2015).

Questão 20 (Enade 2017). Durante o final de temporada de um evento de corrida automobilística, é comum chover nos dois dias de treino, sexta-feira e sábado, e no dia da corrida, domingo. Suponha que a previsão meteorológica para esses dias indique $80 \%$ de chance de chuva para cada um dos dias de treino e $30 \%$ de chance de chuva para o dia da corrida. Considerando as informações do texto acima, avalie as afirmações a seguir.

I. A chance de não chover em nenhum dos três dias é de $2,8 \%$.

II. A chance de chover em pelo menos um dos três dias é de $97,2 \%$.

III. A chance de chover sexta-feira e sábado é de $80 \%$.

É correto o que se afirma em:

(a) I, apenas. (b) III, apenas. (c) I e II, apenas. (d) II e III, apenas. (e) I, II e III.

Quadro 4 - Análise praxiológica da questão 20 do Enade 2017

Tarefa principal (T): Avaliar três afirmações probabilísticas quanto à veracidade.

Técnica principal $(\tau)$ : Resolver cada uma das três afirmações para verificar sua veracidade.

Tarefa $\left(\mathbf{T}_{1}\right)$ : Calcular a probabilidade de união de eventos independentes.

Técnica $(\tau)$ : 1. Identificar a experiência aleatória em jogo observar os três dias determinados para constatar a ocorrência ou não de chuva.

2. Construir a árvore de possibilidades, identificando os eventos do espaço amostral e as probabilidades correspondentes de eventos consecutivos.

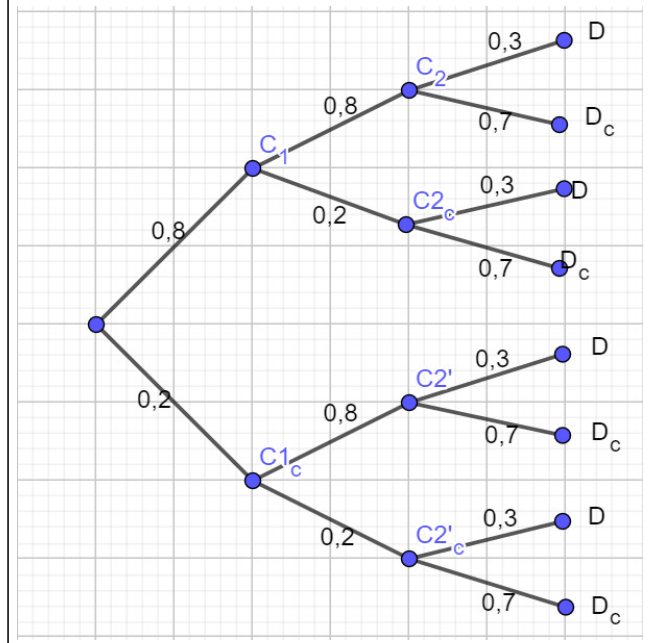

3. Calcular a probabilidade da intersecção de eventos independentes:

$\mathrm{P}\left(\mathrm{C} 1_{\mathrm{c}} \cap \mathrm{C} 2_{\mathrm{c}} \cap \mathrm{D}_{\mathrm{c}}\right)=0,2 \cdot 0,2 \cdot 0,7=0,028$ ou $2,8 \%$, o que implica que a afirmação I é verdadeira.

Tarefa $\left(\mathbf{T}_{2}\right)$ : Determinar a probabilidade da união de eventos (chance de chover em pelo menos um dos três dias.)

As técnicas 1 e 2 da tarefa $\left(T_{1}\right) 1$ e 2 são as mesmas para $\left(T_{2}\right)$.

3. Calcular a probabilidade do evento complementar:

A chance de chover em pelo menos um dos três dias é o evento complementar de não chover em nenhum dos três dias. Logo, $1-0,028=0,972$ ou $97,2 \%$, o que implica que a afirmação II é verdadeira.

Tarefa $\left(\mathbf{T}_{3}\right)$ : Calcular a probabilidade da união de eventos (a probabilidade de chover sexta e sábado).

As técnicas 1 e 2 da tarefa $\left(\mathrm{T}_{1}\right)$ são as mesmas para $\left(\mathrm{T}_{3}\right)$.

3. Calcular a probabilidade da união de eventos:

$\mathrm{P}(\mathrm{C} 1 \cap \mathrm{C} 2)=\mathrm{P}(\mathrm{C} 1 \cap \mathrm{C} 2 \cap \mathrm{D})+\mathrm{P}\left(\mathrm{C} 1 \cap \mathrm{C} 2 \cap_{\mathrm{D}}\right)=$

$=0,8 \cdot 0,8 \cdot 0,3+0,8 \cdot 0,8 \cdot 0,7=0,8 \cdot 0,8^{\mathrm{c}}(0,3+0,7)=0,64$ ou $64 \%$,

o que significa que a afirmação III é falsa.

Tarefa principal $(\tau)$ : decidir pela opção correta

A opção correta é a C: apenas I e II estão corretas.

Tecnologia [0]: Se A e B são independentes, então $\mathrm{P}(\mathrm{A} \cap \mathrm{B})=$ $\mathrm{P}(\mathrm{A}) \cdot \mathrm{P}(\mathrm{B})$.

Se $\mathrm{A} \cap \mathrm{B}=\varnothing$, então $\mathrm{P}(\mathrm{A} \cup \mathrm{B})=\mathrm{P}(\mathrm{A})+\mathrm{P}(\mathrm{B})$. Propriedade distributiva da multiplicação em relação à adição de números decimais.

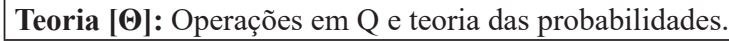
Fonte: Dados da pesquisa.

Questão 21 (Enade de 2017). Seis estudantes se inscreveram para um campeonato escolar de xadrez: três meninas, das quais duas são irmãs gêmeas, e três meninos. Na primeira rodada serão formadas três duplas de adversários por sorteio, da seguinte forma: o primeiro jogador é sorteado entre os seis participantes; o segundo é sorteado entre os cinco restantes; o terceiro entre os quatro restantes; o quarto, entre os três restantes; a primeira dupla é formada pelo primeiro e segundo sorteados; a segunda dupla é formada pelo terceiro e quarto sorteados; a terceira dupla é formada pelos dois últimos que não foram sorteados.

Considerando essas condições a respeito da formação das duplas de adversários na primeira rodada do campeonato, avalie as afirmações a seguir:

I. A probabilidade de as gêmeas se enfrentarem é de 1/15.

II. A probabilidade de a primeira dupla sorteada ser de meninos é de $1 / 15$.

III. A probabilidade de a primeira dupla sorteada ser composta por uma menina e um menino é de $3 / 5$. É correto o que se afirma em:

(a) I, apenas. (b) II, apenas. (c) I e III, apenas. (d) II e III, apenas. (e) I, II e III.

Quadro 5 - Análise praxiológica da questão 21 do Enade 2017

Tarefa principal (T): Avaliar três afirmações probabilísticas quanto à veracidade.

Técnica principal $(\tau)$ : Resolver cada uma das três afirmações para verificar sua veracidade.

Tarefa $\left(\mathbf{T}_{1}\right)$ : Calcular a probabilidade de união de eventos dependentes (as gêmeas estarem em uma das três duplas) 
Técnica $(\tau):$ 1. Identificar a experiência aleatória - formação das três duplas na primeira rodada.

2. Identificar a dependência dos eventos.

3. Calcular o número de elementos do espaço amostral:

Calcular o número de elementos dos eventos as gêmeas estarem na primeira dupla ou estarem na segunda dupla ou estarem na terceira dupla. Uma das técnicas pode ser por meio de conceitos de análise combinatória.

4. Calcular a probabilidade dos eventos condicionados. O cálculo dessas probabilidades envolve cálculo de probabilidade condicional.

5. Calcular a probabilidade da união de eventos. Calcular a probabilidade da união dos eventos dependentes (parte de um espaço amostral).

Esses cálculos permitem constatar que a afirmação I é falsa.

Tarefa $\left(\mathbf{T}_{2}\right)$ : Calcular a probabilidade do evento condicional (a primeira dupla sorteada ser de meninos).

Técnica $(\tau)$ : 1. Identificar a experiência aleatória - a primeira dupla sorteada ser de meninos.

2. Identificar a dependência dos eventos (escolha do segundo elemento da dupla depende da primeira escolha).

3. Calcular a probabilidade do evento condicionado.

Esses cálculos permitem constatar que a afirmação II é verdadeira.

Tarefa $\left(\mathbf{T}_{3}\right)$ : Calcular a probabilidade do evento (a primeira dupla sorteada ser composta por uma menina e um menino).

As técnicas da tarefa $\left(\mathrm{T}_{1}\right)$ e $\left(\mathrm{T}_{2}\right)$ são as mesmas para $\left(\mathrm{T}_{3}\right)$ e esses cálculos permitem constatar que a afirmação é verdadeira.

\section{Técnica principal $(\tau)$ : decidir pela opção correta}

A opção correta é D: apenas II e III estão corretas.

Tecnologia [0]: Se $A$ e $B$ são dependentes, então $P(A \cap B)$ $=\mathrm{P}(\mathrm{A}) \cdot \mathrm{P}(\mathrm{B} / \mathrm{A})$, sendo $\mathrm{A}$ e $\mathrm{B}$ dois eventos quaisquer, com $\mathrm{P}(\mathrm{B})$ $>0$. Sendo três os eventos, $\mathrm{A}, \mathrm{B}, \mathrm{C}$, temos $\mathrm{P}(\mathrm{A} \cap \mathrm{B} \cap \mathrm{C})=\mathrm{P}(\mathrm{A})$ - $\mathrm{P}(\mathrm{B} / \mathrm{A}) \cdot \mathrm{P}(\mathrm{C} / \mathrm{A} \cap \mathrm{C})$. Cálculo da quantidade de elementos por análise combinatória.

Teoria [@]: Análise combinatória e teoria das probabilidades. Fonte: Dados da pesquisa.

Questão 13 (Enade 2014). Muitos fenômenos probabilísticos seguem uma lei de distribuição denominada Normal, na qual os valores mais frequentes se encontram próximos à média. A curva que representa essa distribuição tem a forma de um sino, é simétrica em torno da média $\mu$, tem no eixo das abscissas uma assíntota horizontal e é determinada pela seguinte função de densidade:

$$
f(x)=\frac{1}{\sqrt{2 \pi \sigma^{2}}} e^{-\frac{1}{2}\left(\frac{x-\mu}{\sigma}\right)^{2}}
$$

Levando em consideração que cada curva de distribuição Normal é determinada pela sua média $\mu$ e pelo seu desviopadrão $\sigma$, Gauss desenvolveu uma forma de padronizá-las em uma única Normal, caracterizada por ter média O e desviopadrão 1. Assim, a Normal Padrão é determinada pela função

$$
\mathrm{f}(\mathrm{z})=\frac{1}{\sqrt{2 \pi}} \mathrm{e}^{-\frac{\mathrm{z}^{2}}{2}}
$$

na qual cada um dos valores $x$ da função de distribuição Normal $\mathrm{N}(\mu, \sigma)$ é convertido em uma nova variável adimensional, designada genericamente por $z$, a qual tem distribuição Normal $\mathrm{N}(0,1)$. A conversão dessa variável se dá por meio da seguinte expressão:

$$
\mathrm{z}=\frac{\mathrm{x}-\mu}{\sigma}
$$

Sabe-se que a área sob o gráfico da função de densidade de probabilidade em determinado intervalo fornece a probabilidade de ocorrência de um valor dentro desse intervalo. Assim, considera-se que a área entre a curva Normal e a assíntota determinada pelo eixo das abscissas é igual a 1 .

De acordo com dados obtidos no portal do INEP/MEC relativos aos 11303 estudantes de Licenciatura em Matemática que realizaram a prova do Enade em 2011, a média e o desvio-padrão do desempenho geral desses estudantes foram, respectivamente, iguais a 32,4 e 11,6 pontos. Considerando que a distribuição do desempenho desses alunos no Enade 2011 pode ser aproximada pela distribuição Normal, assinale a alternativa cuja expressão fornece o percentual de estudantes com desempenho inferior a 20,8 pontos ou superior a 55,6 pontos.
(a) $\int_{-1}^{2} f(z) d z$.
(b) $\int_{20,8}^{55,6} f(z) d z$.

(c) $1-\int_{-1}^{2} f(z) d z$.

(d) $\int_{11,6}^{32,4} f(z) d z$

(e) $1-\left(\int_{-\infty}^{-1} f(z) d z+\int_{2}^{\infty} f(z) d z\right)$.

Quadro 6 - Análise praxiológica da questão 13 do Enade 2017

Tarefa (T): Sortear um estudante de licenciatura em matemática e representar o cálculo da probabilidade através de uma integral, considerando-se uma distribuição normal.

Técnica $(\tau):$ 1. Identificar que o enunciado da questão descreve o comportamento de uma distribuição normal, assim como uma possível sequência de técnicas a seguir para resolver a tarefa.

2. Identificar no esboço de um gráfico o comportamento de uma curva normal e os intervalos do enunciado.

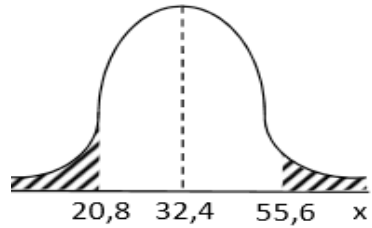


3. Calcular os novos intervalos padronizados pela distribuição normal.

$$
\begin{aligned}
& Z=\frac{X-\mu}{\sigma} \\
& X_{1}=20,8 \Rightarrow Z=\frac{20,8-32,4}{11,6}=-1 \\
& X_{2}=55,6 \Rightarrow Z=\frac{55,6-32,4}{11,6}=2
\end{aligned}
$$

4. Identificar na área desejada os novos intervalos e as propriedades da distribuição normal.
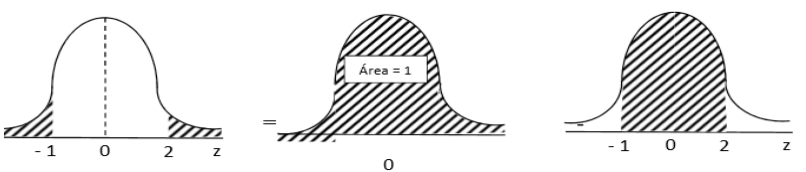

5. Calcular na expressão que representa a área do intervalo a probabilidade:

$\mathrm{P}(\mathrm{X}<20,8)+\mathrm{P}(\mathrm{Z}<55,6)=\mathrm{P}(\mathrm{Z}<-1)+\mathrm{P}(\mathrm{Z}>2)=$

$=1-\mathrm{P}(-1<\mathrm{Z}<2)=1-$

Tecnologia $[\theta]$ : Modelo probabilístico de variáveis aleatórias contínuas; probabilidade geométrica.

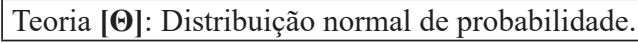

Fonte: Dados da pesquisa.

Nas questões do Enade de 2014 e 2017, identificamos as tarefas de calcular a probabilidade de eventos condicionais, calcular a probabilidade de união de eventos independentes, calcular a probabilidade de união de eventos dependentes e representar o cálculo da probabilidade por meio de uma integral (considerando haver distribuição normal).

Comparando essas tarefas com as identificadas por Goulart (2015) e com as encontradas em provas posteriores, identificamos mudanças não restritas aos conteúdos curriculares apontados nos editais do Enade de 2014 e 2017. Em termos de organizações matemáticas, surgiram nas questões novas tarefas, associadas a outros tipos de técnicas de resolução, abrangendo tecnologias e teoria relativas a tais técnicas. Goulart (2015) relata que as questões do Enade e do ENEM envolviam até então as mesmas organizações matemáticas, mas não podemos afirmar o mesmo, por ser ainda necessário investigar se houve também mudanças nas questões do ENEM relativas à probabilidade durante esse período. (Tal análise está programada como prosseguimento da presente pesquisa.)

O Enade de 2014 e 2017 não requereu que o aluno explicitasse como tais questões foram resolvidas, por serem de múltipla escolha. Muitas vezes os alunos respondem por exclusão, ao conhecerem parte das técnicas envolvidas, sem necessariamente dominarem a tecnologia (atitudes procedimentais), ou mesmo por conhecerem a tecnologia embora a técnica lhes seja muito complexa.

O relatório de análise dos resultados do Enade 2014 (Brasil, 2015) traz índices de facilidade e de discriminação das questões objetivas do componente de conhecimento específico da prova de matemática (bacharelado). Para a questão 13 , o índice de facilidade foi 0,46 , considerado médio, para alunos do bacharelado, mas na mesma questão para alunos de licenciatura em matemática tal índice foi 0,19: uma questão difícil. Tal contraste permite a hipótese de que, pelo fato de as DCN de licenciatura não incluírem probabilidade como disciplina obrigatória, pode ter havido diferença frente ao conhecimento probabilístico de alunos de bacharelado em matemática.

Em provas do Enade anteriores a 2014, Goulart (2015) não identificou questões sobre probabilidade que mobilizassem tais conteúdos, mas a questão 13 do Enade 2014 mostra uma mudança de cenário.

No relatório de análise dos resultados do Enade 2017 (Brasil, 2018b), para questões objetivas do componente de conhecimento específico da prova de matemática da licenciatura, as questões 20 e 21 receberam índices de facilidade 0,23 e 0,29, respectivamente - ou seja, ambas foram consideradas difíceis. Já para o bacharelado, esses índices subiram respectivamente para 0,47 e 0,36. Para alunos de licenciatura, as questões sobre probabilidade estão entre as de menor número de acertos.

Considerando o letramento probabilístico ( $\mathrm{Gal}, 2005)$, cada um dos elementos apresentou as seguintes características:

- Grandes tópicos: As questões abordam tópicos fundamentais, como variação, aleatoriedade, independência, previsibilidade e incerteza - tópicos estes identificados nos quadros de análise das tarefas.

- Cálculos probabilísticos: As escolhas das técnicas possíveis para resolver os problemas revelam o uso de cálculos predominantemente complexos, também devido à complexidade do enunciado, indicando imbricação de elementos do modelo.

- Linguagem: Desde a identificação do enunciado do problema em língua natural, para estabelecer relação entre eventos, até o cálculo de suas probabilidades em forma de fração ou porcentagem, as notações utilizadas foram simbólicas ou compareceram como diagramas de árvore. Destacamos a complexidade desse item no modelo (Gal, 2005), o que justifica o grau de dificuldade atribuído às questões, como já exposto.

- Contexto: As questões de 2017 envolveram jogos. Tanto nesse ano quanto em 2014, foram utilizados contextos próximos ao cotidiano de licenciandos em matemática, o que contribuiu para que não houvesse aumento da complexidade das questões.

- Questões críticas: Pode ser que os alunos reflitam sobre as questões de probabilidade da prova, embora isso não possa ser identificado nas questões analisadas. Os contextos propostos e as organizações matemáticas identificadas, porém, não envolvem questões críticas sobre aplicações probabilísticas. Quanto aos elementos disposicionais, que envolvem postura crítica, crenças e atitudes e também sentimentos pessoais sobre incerteza e riscos, não foi possível identificar sua presença, pelas características das organizações matemáticas identificadas.

Embora nossa proposta de análise não tenha se fundamentado na análise das organizações didáticas, que possibilitam e administram os processos de estudo (Gascón, 2003), um rápido olhar nos permite inferir que estas questões relativas à probabilidade não dão margem a avaliar elementos disposicionais, tal como explicitado no modelo de Gal (2005). 


\section{Considerações Finais}

Analisamos as questões do Enade de 2014 e 2017 quanto a conhecimentos de probabilidade para identificar a presença de elementos do letramento probabilístico, como conceituados por Gal (2005), guiando-nos também pela TAD, com o olhar da organização praxiológica, no intuito de verificar se essa organização contribui para o desenvolvimento do letramento probabilístico do futuro professor de matemática. Para isso, analisamos documentos oficiais que orientam a educação básica e diretrizes dos cursos de matemática e de provas de larga escala, a fim de observar como a probabilidade é focalizada nessas fontes.

Identificamos que a BNCC (Brasil, 2018a) advoga que a probabilidade, juntamente com a estatística, deva constituir objeto de conhecimento em todos os nove anos do ensino fundamental, diferentemente dos PCN (Brasil, 1998), em que essa recomendação não era explícita. A BNCC também salienta o cálculo de probabilidade por meio de muitas repetições de um experimento, frisando as frequências de ocorrência associadas à probabilidade frequentista.

$\mathrm{Na}$ BNCC (Brasil, 2018a), as orientações sobre probabilidade para o ensino médio não são tão claras e específicas como o são para cada ano do ensino fundamental. São explicitadas habilidades a serem desenvolvidas (que implicitamente podemos associar aos objetos de conhecimento correspondentes), para que as instituições federais, estaduais ou municipais possam montar seus próprios currículos e adaptar tais objetos de acordo com suas próprias concepções.

Nas DCN (Brasil, 2002a) de licenciatura em matemática, observa-se um descompasso na ausência da obrigatoriedade dos conteúdos de probabilidade, tanto em termos de atuação do futuro professor na educação básica quanto no preparo para o Enade, a que os licenciados se submeterão no final do curso. Já nas diretrizes para as licenciaturas, as DCN-Formação (Brasil, 2019), que entrarão em vigor em 2022, apontam a necessidade de que entre os objetos de conhecimento estudados também se incluam os que já constam na BNCC (2018).

Embora a probabilidade não constitua objeto de conhecimento obrigatório nas licenciaturas, o Enade contempla questões que envolvem tal tópico, o qual, a partir de 2014, passou a constar nas orientações para esse exame.

Nas provas de 2014 e 2017, foram observadas questões para cuja resolução o conhecimento de probabilidade da educação básica não se mostraria suficiente - achado este que difere do obtido por Goulart (2015) -, daí a necessidade de que a licenciatura em matemática disponha de disciplinas que contemplem essa área.

A análise de elementos do letramento probabilístico (Gal, 2005) e a utilização da TAD revelaram nas questões do Enade uma evolução em relação às provas anteriores, tanto em termos de tarefas, técnicas, tecnologias e teorias quanto de elementos cognitivos do letramento. No entanto, por ser o Enade um instrumento avaliativo constituído de questões de múltipla escolha, não observamos a presença de elementos disposicionais, o que nos impede de inferir sobre o desenvolvimento completo do letramento probabilístico pelos alunos concluintes dos cursos de licenciatura em matemática.

\section{Referências}

Almouloud, S. (2007). Fundamentos da didática da matemática. Curitiba: UFPR.

Brasil (1997). Parâmetros curriculares nacionais. Brasília: Ministério da Educação e do Desporto.

Brasil (1998). Parâmetros curriculares nacionais. Brasília: Ministério da Educação e do Desporto.

Brasil (1999). Parâmetros curriculares nacionais, ensino médio: ciências da natureza, matemática e suas tecnologias. Brasília: Ministério da Educação e do Desporto.

Brasil (2001). Ministério da Educação. Diretrizes curriculares nacionais para os cursos de matemática, bacharelado e licenciatura. Parecer CES/CNE 1.302/ 2001, homologação publicada no Diário Oficial da União, seção 1 , p. 15, em $5 / 3 / 2002$

Brasil (2002a). Diretrizes curriculares nacionais para a formação de professores da educação básica, em nível superior, curso de licenciatura, de graduação plena. Parecer CNE/CES 9/2001, homologação publicada no Diário Oficial da União, seção 1, p. 31, em 18/1/2002.

Brasil (2002b). Parâmetros curriculares nacionais, ensino médio +: ciências da natureza, matemática e suas tecnologias. Brasília: Ministério da Educação e do Desporto.

Brasil (2006). Orientações curriculares para o ensino médio: ciências da natureza, matemática e suas tecnologias. Brasília: Ministério da Educação e do Desporto.

Brasil (2009). Ministério da Educação. Secretaria de Educação Média e Tecnológica. Matriz de referência para o ENEM. Brasília: INEP.

Brasil (2015). Relatório-síntese de área matemática 2014 (bacharelado/licenciatura). Brasília: MEC.

Brasil (2018a). Ministério da Educação. Base nacional comum curricular: BNCC. Brasília: MEC.

Brasil (2018b). Relatório-síntese de área matemática 2017 (bacharelado/licenciatura). Brasília: MEC.

Brasil (2019). Diretrizes curriculares nacionais para a formação inicial de professores para a educação básica e base nacional comum para a formação inicial de professores da educação básica (BNC-Formação). Parecer CNE/CP 22, de 7 de novembro de 2019, homologado pela portaria 2.167, publicada no Diário Oficial da União, seção 1, p. 142, em 20/12/2019.

Chevallard, Y. (1999). L'analyse des pratiques enseignantes en théorie anthropologique du didactique. Recherches em Didactique des Mathématiques, 19(2), 221-265

Coutinho, C. Q. S. (2013). Introdução ao conceito de probabilidade e os livros didáticos para ensino médio no Brasil. In A. Salcedo (org.), Educación estadística en américa latina: tendencias y perspectivas, pp. 193-210. Caracas: Universidad Central de Venezuela.

Coutinho, C. Q. S. (2019). Probabilidade: contexto e construção do letramento probabilístico. In J. M. Contreras, M. M. Gea, M. M. López-Martín, \& E. Molina-Portillo, Actas del Tercer Congreso International Virtual de Educación Estadística. 
Fiorentini, D. \& Lorenzato, S. (2009). Investigação em educação matemática: percursos teóricos e metodológicos. Campinas: Editores Associados.

Gal, I. (2005). Towards "probability literacy" for all citizens: building blocks and instructional dilemmas. In G. A. Jones (ed.), Exploring probability in school: challenges for teaching and learning, pp. 39-63. Boston, MA, United States: Springer.

Gascón, J. (2003). La necesidad de utilizar modelos en didáctica de las matemáticas. Educ. Matem. Pesq., 5(2), 11-37).

Goulart, A. (2007). O discurso sobre os conceitos probabilísticos para a escola básica. São Paulo: Pontifícia Universidade Católica de São Paulo.

Goulart, A. (2015). Um estudo sobre a abordagem dos conteúdos estatísticos em cursos de licenciatura em matemática: uma proposta sob a ótica da ecologia do didático. Tese de doutorado. Pontifícia Universidade Católica de São Paulo, São Paulo.

Oliveira, G. P. (2019). A elaboração do problema de pesquisa em educação matemática. In G. P. Oliveira. Pesquisa em educação e educação matemática: um olhar sobre a metodologia. Curitiba: CRV.
Pereira, F.A. \& Souza, F.S.S. (2016). O Exame Nacional do Ensino Médio e a construção do letramento e pensamento estatístico. Educ. Matem. Pesq., 18(3), 1319-1343. doi: https://doi.org/10.1590/s0104-40362019002701489

Rodrigues, M. R. (2018). Estudo sobre as concepções de professores do ensino básico em relação à aleatoriedade $\mathrm{e}$ probabilidade. Tese de doutorado. Pontifícia Universidade Católica de São Paulo, São Paulo.

Rodrigues, M. U. \& Silva, L. D. (2019) Disciplina de estatística na matriz curricular dos cursos de licenciatura em matemática no Brasil. Revemat, 14(edição especial: Educação estatística), 1-21). doi: https://doi.org/10.5007/1981-322.2019.e62829

Santos, R. M. (2015). Estado da arte e história da pesquisa em educação estatística em programas brasileiros de pósgraduação. Tese de doutorado. Universidade Estadual de Campinas, Campinas.

Viali, L. (2008). O ensino de estatística e probabilidade nos cursos de licenciatura em matemática. In Sociedade Brasileira de Estatística, Anais do XVIII Simpósio Nacional de Probabilidade e Estatística, pp. 1-7. São Pedro: Sinape. 